\title{
Compassion and efficiency not mutually exclusive in health care
}

\author{
n Cite as: CMAJ 2019 July 8;191:E775-6. doi: 10.1503/cmaj.109-5773
}

Posted on cmajnews.com on June 20, 2019.

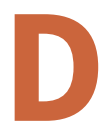

r. Stephen Trzeciak insists that his conversion to "compassionomics" has transformed his life. With the zeal of a true convert, the chief of medicine at Cooper University Health Care in Camden, New Jersey, is now taking his message to a wider medical audience, and early indications are that it's a message people want to hear.

His presentation at the recent Healthcare Leadership and Improvement Conference in Toronto drew a full house of Canadian medical leaders who quickly bought all available copies of his book Compassionomics: The Revolutionary Scientific Evidence that Caring Makes a Difference, cowritten with Dr. Anthony Mazzarelli. The two physician-scientists reviewed some 250 scientific papers referencing compassion before compiling, curating and connecting the findings, then pairing them with stories from the frontlines of medicine. Compassion, they concluded, has the power to transform medicine.

Recognition of the meaningful role compassion plays in medicine is not new. "There have been voices calling for more compassion in health care forever," says Trzeciak. However, Compassionomics takes a novel approach. By looking at compassion from a scientific perspective rather than a moral or ethical one, the authors are able to prove that the importance of compassion is measurable. "This book is really about the 'why.' Why compassion is not only the right thing to do, it's also the smart thing to do in terms of providing the best conditions for healing to occur," says Trzeciak.

The data show that health care outcomes are dependent not only on how much health care providers know but on

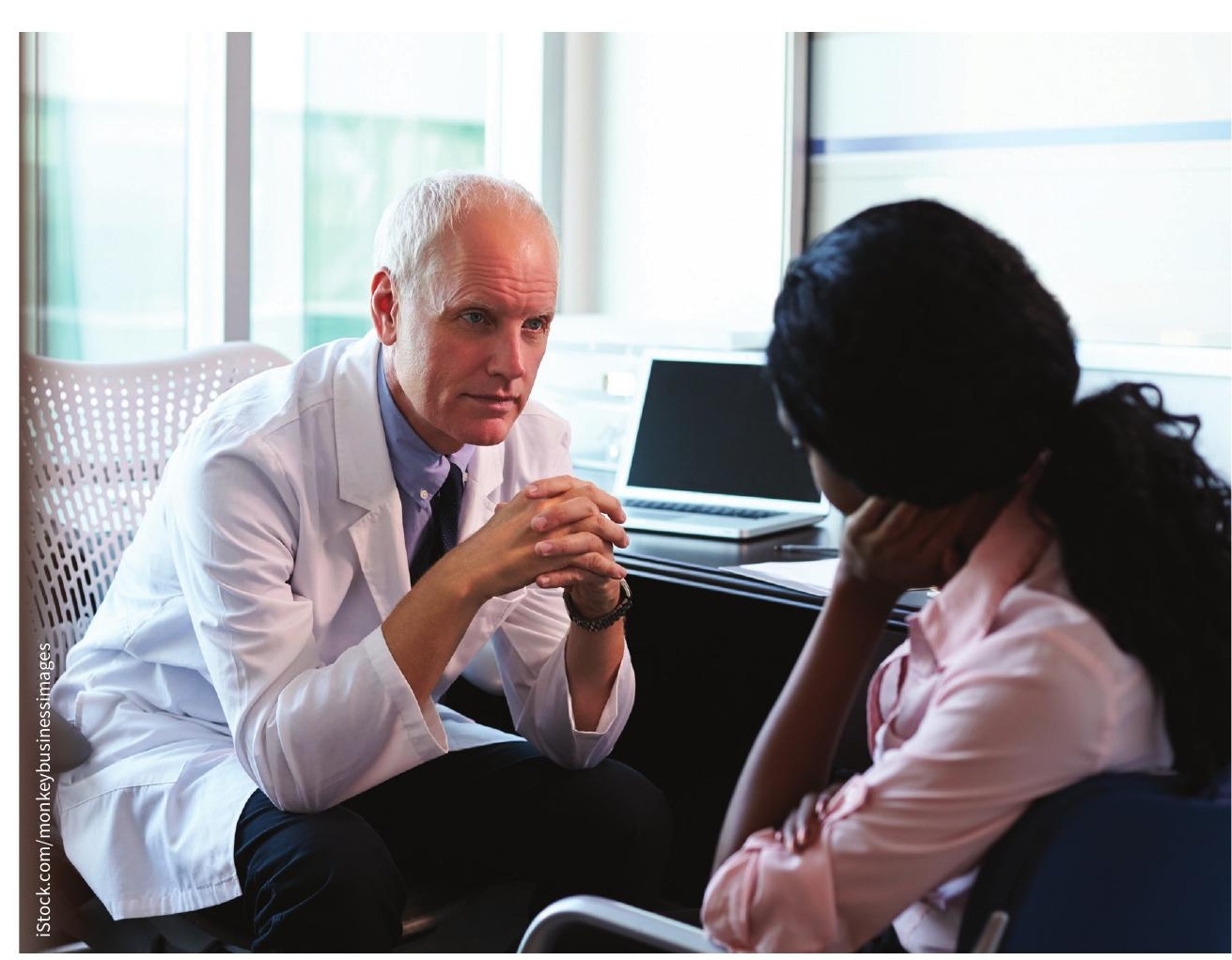

Delivering health care with compassion doesn't take any more time or effort.

how much they care. Compassionate, patient-centred care leads to happier, healthier patients and lower health care costs. There's also evidence that compassion may protect health care providers from burnout. Trzeciak is hoping this accumulated data will drive real change. "Once you realize how powerful you are just through the act of caring, you'll want to get better at compassion every day."

Dr. Lennox Huang appreciates this fresh data-driven approach, calling the book's message "yet another tool in the toolbox of how you shift the culture of your organization." After attending Trzeciak's Toronto talk, the chief medical officer at the Hospital for Sick Chil- dren (SickKids) came away with more ideas on how to use evidence-based stories to push the truth that professionalism and kindness result in safer and higher-quality care.

Just before attending the conference, Huang had sent a letter to staff at SickKids under the heading "kindness," a reminder that even though the pressures of the job are often onerous, thinking carefully about how they treat patients, and each other, must remain a priority. That can be difficult at times, considering the many challenges faced by health care providers. "There's the environment you move in, real systems issues, financial pressures," Huang says, explaining that it 
can be easy to get lost in the science and finance of medicine and forget about the human factor.

Trzeciak has used his platform to stress that the never-ending quest for efficiency is no excuse for letting the human side of medicine slide. "You can go through your daily activities with brusque efficiency and let people know how busy you are, or you can go through your day valuing human connection and showing compassion and it actually doesn't take any longer," he says. To prove his point, he recites a typical conversation he might have with a patient, one that begins their relationship in a respectful and compassionate manner. It takes him 40 seconds.

For Huang, that struck a chord. "Compassion doesn't cost you any more time or effort - it's more about your choice of words, the actions that you take, and the way you convey caring and kindness," he says. "If you set that tone, you're much more likely to get positive feedback from patients and families and that's energizing for you."
Following the positive reception at his Toronto speaking engagement, Trzeciak jokes that, as a scientist, he doesn't yet have an answer as to why he has received a disproportionate amount of attention and affirmation from the Canadian health care establishment, with multiple requests for interviews and offers for further speaking engagements. "Canadians just really seem to get compassionomics and the idea that compassion makes everyone's job easier."

Sarah Brown, Ottawa, Ont. 